\title{
El ingreso de China a la O rganización Mundial de Comercio y el papel de APEC
}

$\mathrm{I}_{\mathrm{t}}^{\mathrm{n}}$ ntroducción marcó para la República Popular China el cambio de una política internacional revolucionaria a otra de mantenimiento del status $q u o^{1}$. Con el ingreso a la Organización Mundial de Comercio (OMC), China ya forma parte de los principales organismos mundiales y la convierten en un actor influyente del sistema internacional. En términos comerciales, por ejemplo, obtiene de manera permanente el "estatus" de nación más favorecida y el derecho a participar en la estructura multilateral que redefine las reglas del comercio mundial y resuelve las disputas.

Después de quince años de negociaciones, el 17 de septiembre de 2001 las partes llegaron a un acuerdo sobre el ingreso de China a la OMC, mismo que fue aprobado días después (el 10 de noviembre), por consenso en la Conferencia de Ministros. El texto legal, de aproximadamente 900 páginas, define los compromisos de apertura y liberalización por medio de los cuales China avanzaría en su integración a la economía mundial y ofrecería un ambiente más predecible para el comercio y la inversión extranjera, de conformidad con las reglas de la OMC (WTO, News Press, 243).

Las negociaciones de China para ingresar a la OMC se hicieron en varios frentes: colaboró, como era debido, con el "Equipo de Trabajo" ad hoc; negoció acuerdos bilaterales con muchos países, en especial con Estados Unidos y la Unión Europea, y utilizó los foros multilaterales para ir creando consenso sobre el avance de las negociaciones y el cumplimiento de los requerimientos impuestos por sus contrapartes, sobre todo a partir de 1992 cuando se dio el

* Investigador del Departamento de Estudios del Pacífico de la Universidad de Guadalajara.

ORCID http://orcid.org/0000-0002-9145-5865 impulso definitivo. Uno de estos foros fue el de Cooperación Económica Asia Pacífico (APEC). Específicamente en las reuniones de jefes de Estado de Osaka, Japón (1995) y de Subic, Filipinas (1996), China realizó anuncios sobre importantes reducciones arancelarias. En las múltiples reuniones de trabajo de este año, en las que China fue país anfitrión, sus representantes insistieron de manera sistemática sobre el cumplimiento de los requisitos para ingresar a la OMC.

\section{Los compromisos de China}

En términos generales, los compromisos adquiridos por China son los siguientes:

- Otorgar tratamiento no discriminatorio para todos los miembros de la OMC. En este punto se pone énfasis en que las personas y empresas extranjeras serán tratadas de manera no menos favorable que las empresas chinas en relación con los derechos comerciales, incluyendo las corporaciones que a la fecha no hayan invertido o no estén registradas en China.

- Eliminar las prácticas de precios duales, así como las diferencias de trato otorgadas a los bienes producidos para su comercialización en China, en comparación con los productos para exportación.

- No utilizar los controles de precios para otorgar protección a las industrias o a los proveedores de servicios domésticos.

- Aplicar el Acuerdo con la OMC de una manera efectiva y uniforme por medio de la revisión de su actual legislación interna y de la aprobación de nuevas leyes, totalmente 
compatibles con el Acuerdo firmado por China con la OMC.

- Todas las empresas tendrán el derecho de importar y exportar a través de las aduanas territoriales todo tipo de bienes, así como comercializarlos dentro de China con algunas excepciones.

- China no mantendrá ni introducirá subsidio alguno a la exportación de productos agrícolas (WTO, News Press, 243).

Al mismo tiempo China se reserva el derecho de llevar a cabo, a través de sus empresas y organismos estatales, el comercio de productos como cereales, tabaco, combustibles y minerales, y mantener algunas restricciones sobre transportación y distribución de bienes dentro del país. Muchas de las restricciones que las empresas extranjeras tienen actualmente en China serán eliminadas o c on siderablemente disminuidas después de tres años. En otras áreas, como los derechos de protección a la propiedad intelectual, China pondrá totalmente en efecto los Acuerdos TRIPS (Aspectos de los Derechos de Propiedad Intelectual Relacionados con el Comercio ), para la fecha de incorporación.

Durante un periodo de 12 años, a partir de la fecha de incorporación, existirá un Mecanismo Especial de Salvaguarda Transicional para los casos en que las importaciones de productos de origen chino causen, o amenacen causar, disrupciones de mercado a los productores domésticos de otros miembros de la OMC

Por otra parte, las prohibiciones, restricciones cuantitativas $u$ otros medidas establecidas contra las importaciones de China, de cierta manera inconsistentes con el Acuerdo con la OMC, serán eliminadas o resueltas de conformidad con los términos y tiempos especificados en el anexo del Protocolo de Incorporación(ibid).

Con el objeto de cumplir con las condiciones mínimas para su ingreso al máximo organismo de carácter comercial, China ha venido realizando una serie de ajustes en su estructura comercial y productiva, así como en $\mathrm{su}$ sistema judicial. Para ir socializando el avance de este proceso, así como para medir las respuestas a sus reformas, el foro de Cooperación Económica de Asia Pacífico (APEC), ha sido crucial. Los mecanismos de carácter "unilateral" y "voluntario", sobre los cuales los países miembros pueden ir haciendo sus ajustes, le han proporcionado a China un cómodo ambiente para la realización de las reformas que cumplan con los requerimientos de sus socios más influyentes dentro de la arena mundial. La "presión de sus pares" dentro de APEC ha cumplido un papel positivo en la apertura del camino hacia la OMC (Hai,1998: 187-188). Tal es así, que los compromisos adquiridos por la dirigencia china con APEC, presentados en su Plan de Acción Individual (PAI), se ajustan en tiempos y procedimientos a lo negociado con la OMC (IAP People's Republic of China, 2001).

En la última versión del Plan de Acción Individual, previa al ingreso a la OMC, China señala que su tarifa de importación, integrada por 7,111 fracciones arancelarias, tienen una tasa arancelaria promedio simple de 15.3 por ciento. La última reducción arancelaria (de 16.4 a 15.3 por ciento), se realizó el $1^{\circ}$ de enero de 2001, e incluyó un total de 3,462 fracciones (49por ciento del total). Con su ingreso a la OMC China se compromete a eliminar los aranceles para todos sus productos y reducir la tasa 


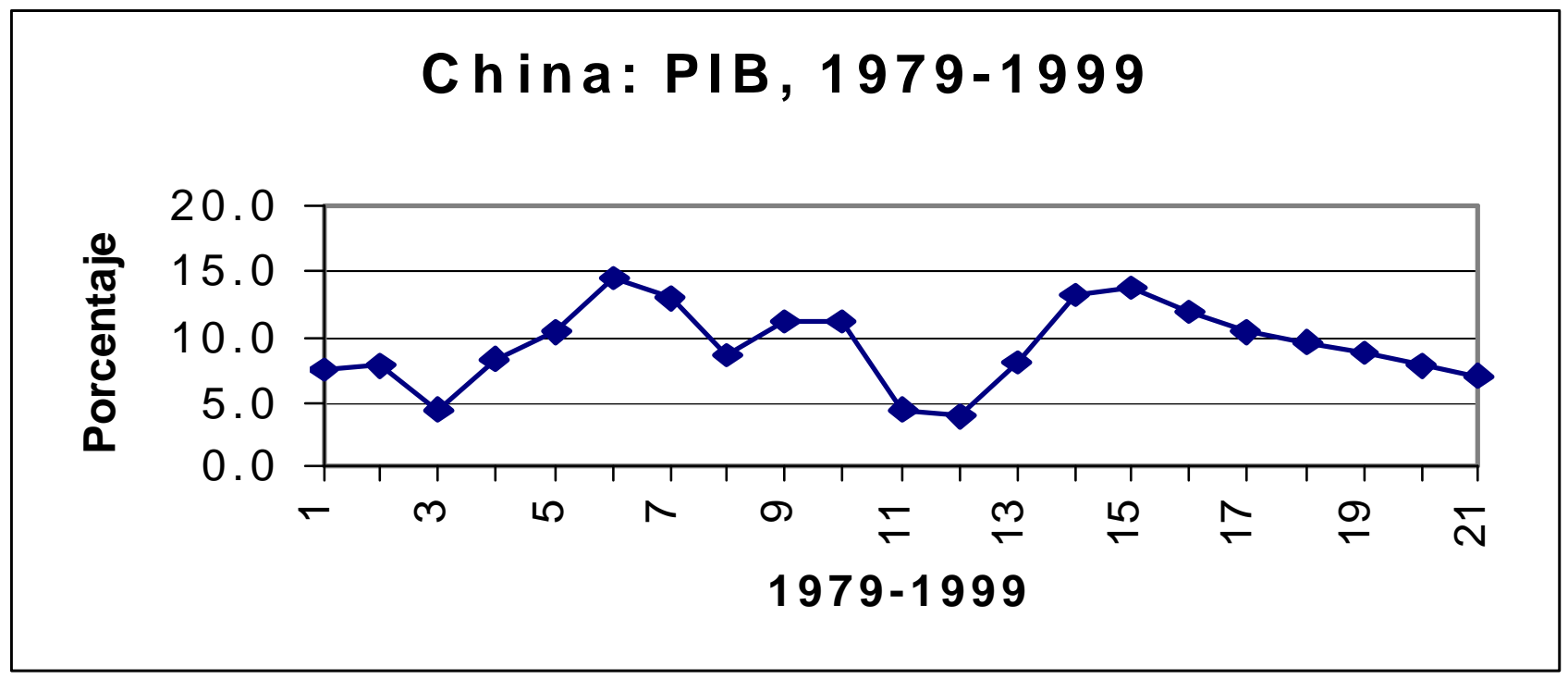

arancelaria de acuerdo con los compromisos programados (IAP, 2001) $)^{2}$. Las restricciones cuantitativas han sido eliminadas para la mayoría de los productos y en su lugar han sido introducidas las cuotas de importación.

El mismo documento apunta que desde 1992 el gobierno chino ha reducido voluntaria y significativamente las medidas no arancelarias sujetas a cuotas de importación, licencias y requerimientos de pago. Para septiembre de 2001, sólo 351 fracciones arancelarias (HS 1996,8-digitlevel) de productos de importación estaban aún sujetos a requisitos no arancelarios administrados por el gobierno central, las cuales equivalen al 5 por ciento del total de las fracciones arancelarias de importación. En otras palabras, 20 fracciones arancelarias de productos de importación, previamente sujetos a medidas no arancelarias, fueron eliminados en 2001 y un total de 896 fracciones, previamente sujetas a medidas no arancelarias han sido eliminados en los pasados 10 años. Después del acceso de China a la OMC el gobierno chino gradualmente eliminará las medidas no arancelarias de acuerdo con los compromisos establecidos (IAP, 2001, 6).

\section{El contexto general}

Es referencia obligada, para el caso de China, encuadrar la incorporación de China al máximo organismo mundial de comercio dentro del proceso de La Reforma que definieron los ajustes de carácter económico y comercial que sirvieron de plataforma para su incorporación a la OMC. La transición hacia una economía de mercado y la apertura hacia el exterior son dos elementos esenciales que caracterizan el amplio proceso de ajuste institucional, político, cultural y económico, iniciado a finales de los 70. Los resultados de carácter económico los podemos medir por los niveles de crecimiento en el Producto Interno Bruto (PIB), logrados por China desde entonces. Estos niveles sin precedentes son comparables a los alcanzados por Japón y Corea en sus mejores tiempos; con la diferencia de que China los ha mantenido por un periodo más largo y que dispone de una plataforma mucho mayor de recursos naturales y humanos. Medido en términos del PIB, China creció a una tasa promedio anual de 9.3 por ciento en los 21 años que van de 1979 a 1999 , como se aprecia en la siguiente gráfica.

El crecimiento económico del año 2000, aunque menor al promedio de los últimos 21 años, alcanzó el 8 por ciento; para 2001 en que se esperaba una reducción a 7.5 por ciento, de acuerdo con la tendencia de estos meses, se espera que conserve un nivel igual al del año pasado. De acuerdo con la previsiones del $10^{\circ}$ Plan Quinquenal (2001-2005), el crecimiento económico sería de 7.2 por ciento anual durante 


\section{Cuadro 1}

\section{Comercio exterior de China, 1990-1999}

(miles de millones de dólares y variación anual en \%)

\begin{tabular}{|c|c|c|c|c|c|}
\hline & \multicolumn{2}{|c|}{ Exportaciones } & \multicolumn{2}{|c|}{ Importaciones } & \multirow[t]{2}{*}{ Saldo } \\
\hline & Valor & Variación & Valor & Variación & \\
\hline 1990 & 62.09 & & 53.35 & & 8.74 \\
\hline 1991 & 71.84 & 15.70 & 63.79 & 19.57 & 8.05 \\
\hline 1992 & 84.94 & 18.23 & 80.59 & 26.34 & 4.35 \\
\hline 1993 & 91.74 & 8.01 & 103.96 & 29.00 & -12.22 \\
\hline 1994 & 121.01 & 31.91 & 115.61 & 11.21 & 5.40 \\
\hline 1995 & 148.78 & 22.95 & 132.08 & 14.25 & 16.70 \\
\hline 1996 & 151.05 & 1.53 & 138.83 & 5.11 & 12.22 \\
\hline 1997 & 182.79 & 21.01 & 142.37 & 2.55 & 40.42 \\
\hline 1998 & 183.76 & 0.53 & 140.17 & -1.55 & 43.59 \\
\hline 1999 & 194.90 & 6.06 & 165.70 & 18.21 & 29.20 \\
\hline 2000 & 249.00 & 27.76 & 225.00 & 35.79 & 24.00 \\
\hline
\end{tabular}

FUENTE: Chinability. Datos de China Statistical Yearbook, China Statistics Press, 1999; Word Trade Organization, [http: /www.wto.org] (20/11/01).

el periodo. Sin embargo, algunos analistas esperan que el ingreso a la $\mathrm{OMC}$ estimule el crecimiento económico en 1 ó 1.5 por ciento más.

La cifras anteriores se perciben en la economía real de la siguiente manera: China ha incrementado la producción de alimentos por encima del crecimiento poblacional y mantenido un nivel de autosuficiencia alimentaria cercana al 100 por ciento. Además este país se ha convertido en una potencia industrial. Por ejemplo: es el principal productor de acero, carbón, cemento, ropa y televisores del mundo, y se ubica entre los cinco primeros productores mundiales de electricidad y petróleo. Asimismo, es el mayor exportador de ropa (con el 25 por ciento del mercado mundial), textiles, juguetes, algodón y calzado. El sur de China se ha convertido en una importante área de tecnología informática.

Asimismo, el rápido crecimiento económico se ha reflejado en un incremento de los niveles de ingreso en la mayoría de las ciudades y poblados de la costa, equiparables a los de algunos países de nivel medio, hecho que ha motivado el interés de muchas empresas extranjeras por acceder a un mercado con gran potencialidad (Ippei 2001, prefacio).

No hay duda de que la inserción de China a la OMC profundizará el proceso de ajuste institucional de los últimos veinte años e incidirá sobre la política multilateral y la economía, la sociedad y la política de varios países con los que ha ido intensificando sus lazos comerciales. Aunque son previsibles y cuantificables muchas de las repercusiones de este evento, otras tantas habrá que irlas evaluando conforme se den los cambios de carácter político y administrativo dentro y fuera de China. Algunos de los aspectos más significativas de los sectores en los que incidirá el acceso de este país a la OMC, son las siguientes:

\section{Comercio Exterior}

La integración de China a la OMC facilitará el acceso de sus productos al mercado mundial, al mismo tiempo que garantiza el acceso de los productos y servicios del exterior. En consecuencia, se prevé un crecimiento tanto de 
Cuadro 2

Valor del comercio mundial en el 2000

e incremento anual en el valor del comercio mundial por región, 1990-2000

(miles de millones de dólares $y$ porcentaje)

\begin{tabular}{|c|c|c|c|c|c|c|}
\hline & \multicolumn{3}{|c|}{ Exportaciones } & \multicolumn{3}{|c|}{ Importaciones } \\
\hline & \multicolumn{2}{|c|}{2000} & \multirow{2}{*}{$\begin{array}{c}\frac{1990-2000}{\text { Aumento }} \\
\text { anual (\%) }\end{array}$} & \multicolumn{2}{|c|}{2000} & \multirow{2}{*}{$\begin{array}{r}1990-2000 \\
\begin{array}{c}\text { Aumento } \\
\text { anual (\%) }\end{array}\end{array}$} \\
\hline & Valor & $(\%)$ & & Valor & $(\%)$ & \\
\hline Mundo & 6,186 & 100.0 & 6.0 & 6,490 & 100.0 & 6.0 \\
\hline América del norte & 1,058 & $\begin{array}{c}17.1 \\
-\end{array}$ & 7.0 & 1,504 & $\begin{array}{c}23.2 \\
-\end{array}$ & 9.0 \\
\hline América Latina* & 359 & $\begin{array}{l}5.8 \\
-\end{array}$ & 9.0 & 388 & $\begin{array}{l}6.0 \\
-\end{array}$ & 12.0 \\
\hline $\begin{array}{l}\text { Europa occidental } \\
\text { Unión Europea (15) }\end{array}$ & $\begin{array}{l}2,441 \\
2,251\end{array}$ & $\begin{array}{c}39.5 \\
36.4 \\
-\end{array}$ & $\begin{array}{l}4.0 \\
4.0\end{array}$ & $\begin{array}{l}2,567 \\
2,362\end{array}$ & $\begin{array}{c}39.6 \\
36.4 \\
-\end{array}$ & $\begin{array}{l}4.0 \\
4.0\end{array}$ \\
\hline $\begin{array}{l}\text { Europa C. y O. /países bálticos/CEI } \\
\text { Europa del este y central }\end{array}$ & $\begin{array}{l}271 \\
116\end{array}$ & $\begin{array}{l}4.4 \\
1.9\end{array}$ & $\begin{array}{l}7.0 \\
8.0\end{array}$ & $\begin{array}{l}242 \\
146\end{array}$ & $\begin{array}{l}3.7 \\
2.2\end{array}$ & $\begin{array}{r}5.0 \\
10.0\end{array}$ \\
\hline Federación rusa & 105 & $\begin{array}{l}1.7 \\
-\end{array}$ & - & 46 & $\begin{array}{l}0.7 \\
-\end{array}$ & - \\
\hline Africa & 145 & $\begin{array}{l}2.3 \\
-\end{array}$ & 3.0 & 137 & $\begin{array}{l}2.1 \\
-\end{array}$ & 4.0 \\
\hline Medio Oriente & 263 & $\begin{array}{l}4.3 \\
-\end{array}$ & 7.0 & 171 & $\begin{array}{l}2.6 \\
-\end{array}$ & 6.0 \\
\hline Asia & 1,649 & 26.7 & 8.0 & 1,481 & 22.8 & 8.0 \\
\hline Japón & 479 & 7.7 & 5.0 & 380 & 5.9 & 5.0 \\
\hline China & 249 & 4.0 & 15.0 & 225 & 3.5 & 15.0 \\
\hline Seis economías del este de Asia & 649 & 10.5 & 9.0 & 615 & 9.5 & 8.0 \\
\hline
\end{tabular}

* No incluye a México

FUENTE: World Trade Organization, (http: //wto.org/english/) (20/11/01).

las exportaciones como de las importaciones. En el último decenio el comercio exterior de China, en ambos sentidos, se incrementó de 115.4 mil millones a 360.6 mil millones de dólares de 1990 a 1999 , lo que da un crecimiento de 212 por ciento en 10 años. Tan sólo en el año 2000, el incremento de las exportaciones fue de 27.7por ciento, mientras que el de las importaciones llegó a 35.8 por ciento; en ambos casos en relación con el año anterior (cuadro 1).

Si vemos la dinámica comercial de los últimos diez años a nivel mundial, tenemos que China fue el país que reportó el mayor crecimiento en su comercio exterior, con un 15 por ciento anual, tanto para las exportaciones como para las importaciones. No obstante este crecimiento, China participa en el 4 por ciento de las exportaciones mundiales y con el 3.5 por ciento de las importaciones, en ambos casos muy por debajo de Japón, de Amércia del Norte y de Europa (cuadro 2)

Aunque por otra parte, el saldo positivo de su balanza comercial, logrado en los últimos años (con excepción de 1993), le ha permitido acumular grandes reservas de divisas. De acuerdo con cifras oficiales, China había acumulado para junio de 2001, 180,000 millones de dólares en divisas (Muzi net).

\section{Inversión extranjera}

En el último lustro China recibió un promedio anual de inversión extranjera directa de 41,000 millones de dólares, que equivale, aproximadamente, al 20 por ciento de la inversión fija total. De hecho, la mayoría de las 
Cuadro 3

Volumen de inversión estranjera directa en China 1996-2000

\begin{tabular}{lccr}
\hline & $\begin{array}{c}\text { Número de } \\
\text { proyectos }\end{array}$ & $\begin{array}{c}\text { Volumen } \\
\text { contratado } \\
\text { mill.de dólares }\end{array}$ & $\begin{array}{r}\text { Volumen } \\
\text { ulilizado } \\
\text { mill. de dólares }\end{array}$ \\
\hline 1996 & 25529 & 73,213 & \\
1997 & 21001 & 51,003 & 42,350 \\
1998 & 19799 & 52,102 & 45,257 \\
1999 & 17100 & 41,238 & 45,463 \\
2000 & 17493 & 43,516 & 40,398 \\
& & & 31,402 \\
\hline
\end{tabular}

FUENTE: Ministry of Foreign Trade and Economic Cooperation (MOFTEC) tomado de Ippei, Yamazawa and Imai, Ken-ichi, "China Enters WTO: Pursuing Symbiosis with the Global Economy", Institute of Developing Economies, Tokio, 2001, p. 13

256 ramas industriales de China han recibido inversiones extranjeras en gran escala; sólo han quedado exentos algunos pocos sectores estatales. Actualmente, China es el segundo receptor de Inversión Extranjera Directa, sólo después de los Estados Unidos.(Cuadro 2) Con el ingreso a la OMC, se espera un mayor incremento de las inversiones, sobre todo de las grandes empresas transnacionales.

El ingreso de China a la OMC, incidirá de manera muy significativa en la economía de este país y cambiará sus perfiles social, político y cultural. Los impactos, algunos positivos y otros negativos, se darán en áreas como la agricultura, la banca y los seguros, la industria automotriz, los textiles, la energía y el comercio al menudeo. Veamos algunos de los sectores y dentro de estos, algunas de las ramas donde se esperan los mayores ajustes.

\section{Agricultura}

Las negociaciones sobre agricultura para el ingreso de China a la OMC fueron de las más importantes y difíciles. La reticencia para la apertura de este sector se fundamentó en el hecho de que los agricultores chinos disponen de dotaciones muy pequeñas de tierra y de tecnología atrasada, lo que les impide competir con los grandes productores de los países desarrollados (Estados Unidos, Canadá y Australia), equipados con tecnología moderna (Lin, 2000). Además, ahora los precios de los granos en el mercado chino, en general, superan los del mercado internacional de estos productos (Hernández, 2001).

Como resultado de los acuerdos alcanzados con Estados Unidos. (noviembre de 1999) y la Unión Europea (mayo de 2000), China realizará ajustes a sus niveles de protección de frontera y medidas administrativas sobre las importaciones de productos agrícolas. Los principales aspectos son: a) reducción de la tasa arancelaria a los productos agrícolas del 21.2 por ciento actual a 17 por ciento en 2004 , b) eliminación de medidas no arancelarias en trigo, arroz, maíz, algodón, aceite de soya, azúcar y lana, entre otros, c) eliminación de las barreras sanitarias y fitosanitarias, d) eliminación de los subsidios a las exportaciones agrícolas, y e) aceptación de que las empresas privadas participen en la comercialización de granos básicos (Du, 2001: 55; Lin, 2001; Hernández, 2001)

Los cambios en la legislación y la estructura administrativa interna de China, que originaran los acuerdos comerciales, implican 
una reducción en los controles directos por parte del gobierno en cuanto a producción y comercialización agrícola, incluyendo el manejo de los precios. El sistema de cuotas de importación permitirá a los Estados Unidos exportar a China 14.4 millones de toneladas de granos, inicialmente, e incrementarlos a 21.8 millones en 5 años. Se espera que las exportaciones de Estados Unidos no excedan la cuota, debido a que las tarifas para las importaciones por arriba de la cuotas las harían prohibitivas. Sobre la marcha podrán hacerse lo ajustes necesarios, dependiendo de cómo incida la restructuración productiva sobre los niveles de producción de los granos básicos.

Aparte de los granos, que son intensivos en el factor tierra, China tiene ventajas comparativas en una gran cantidad de otros productos agrícolas intensivos en mano de obra, como frutas y hortalizas, productos pecuarios y acuícolas, así como en productos agrícolas procesados. La medidas concretas, de carácter administrativo, destinadas a reforzar el desarrollo de la agroindustria en las zonas rurales, manifiestas desde 1990, han interrelacionado las operaciones familiares en pequeña escala con los grandes mercados internos y externo. El incremento del valor agregado de la agricultura, por medio de la ampliación de la cadena agroalimentaria, permitirá reforzar la adquisición de tecnología avanzada para el procesamiento de los productos agrícolas intensivos en mano de obra.

De hecho desde el inicio de La Reforma, el comercio agrícola de China ha sido superavitario y ha mostrado un gran crecimiento: pasó de 57 millones de dólares en 1980 a 6,800 en 1999 . Con la eliminación de barreras proteccionistas, como resultado de su participación en la OMC, China podría ampliar significativamente sus mercados externos para los productos agrícolas intensivos en mano de obra (Lin, 2000; Du, 2001:58-59). Hasta ahora China ha tenido una baja participación en el mercado mundial de productos agrícolas (aproximadamente 4por ciento). Esto se debe, fundamentalmente, a que el gobierno chino ha establecido una política destinada a elevar los niveles de autosuficiencia alimentaria; entonces, aunque sea el principal consumidor de alimentos del mundo, también es el principal productor de estos. Esta estructura comercial, muy probablemente cambiará con su participación en la OMC: por un lado importará más granos y oleaginosas, y por el otro exportará bienes agrícolas intensivos en mano de obra, como frutas, hortalizas, estimulantes (té) y productos marinos, cada vez con un mayor grado de procesamiento.

\section{Industria}

El sector industrial, en general, tendrá que realizar ajustes importantes. Las ramas intensivas en mano de obra es posible que sean afectadas en menor medida; no así las intensivas en capital como las productoras de automóviles, petróleo, químicos, maquinaria y otros. El sector agroindustrial, también tendrá efectos significativos. Las ramas que ya poseen ventajas comparativas (productos intensivos en mano de obra) y una capacidad de adaptación a los mercados globales, podrán reportar resultados positivos.

Los sectores con una sólida fuerza de ingenieros y técnicos, y buenas bases educativas, sectores intensivos en conocimiento, especialmente la industria del software, podrán resurgir con mayor fuerza en un marcado globalizado (He, 2001: 3-12)

En el siguiente cuadro se presentan los compromisos de reducción paulatina de tarifas arancelarias de las principales ramas industriales, contenidos en el Acuerdo entre China y la OMC:

\section{Servicios}

Dentro de de este rama son de gran importancia los acuerdos obtenidos en los sectores financieros y de seguros. Con La Reforma, China se ha abierto, paulatina y selectivamente, a la acción de las empresas financieras del exterior y ha eliminado el monopolio que existía por parte del Estado en este sector. Para principios del 2000 los bancos y las instituciones financieras 
Cuadro 4

\begin{tabular}{|c|c|c|c|c|}
\hline Producto & $\begin{array}{l}\text { Tarifa } \\
\text { actual } \\
(\%) \\
\end{array}$ & $\begin{array}{c}\text { Tarifa } \\
\text { acordada } \\
(\%) \\
\end{array}$ & $\begin{array}{l}\text { Fecha de } \\
\text { terminación }\end{array}$ & Observaciones \\
\hline $\begin{array}{l}\text { Equipo } \\
\text { Agrícola }\end{array}$ & 11.54 & $5.7,3$ y 4 & $01 / 2002$ & \\
\hline Automóviles & $\begin{array}{r}\text { de } 75 \\
\text { a } \quad 59.9\end{array}$ & 25 & $07 / 2006$ & $\begin{array}{l}\text { Las cuotas se eliminan en } \\
2005 \text { y parten de } 6,000 \text { mill. } \\
\text { de dólares con aumentos de } \\
15 \text { por ciento anual. }\end{array}$ \\
\hline Química & 14.74 & 6.9 & $01 / 2005$ & $\begin{array}{l}\text { Casi todas las cuotas se } \\
\text { eliminan con el acceso. } \\
\text { Las restantes en el } 2002 .\end{array}$ \\
\hline $\begin{array}{l}\text { Equipo de } \\
\text { Construcción }\end{array}$ & 13.6 & 6.4 & $01 / 2004$ & \\
\hline Cosméticos & 45 & 10 y 15 & 2004 y 2005 & \\
\hline Muebles: & 22 & 0 & $01 / 2005$ & \\
\hline $\begin{array}{l}\text { Tecnología } \\
\text { de información }\end{array}$ & 13 & 0 & $\begin{array}{l}01 / 2003 \\
01 / 2005\end{array}$ & Dependiendo del producto \\
\hline $\begin{array}{l}\text { Equipo } \\
\text { médico }\end{array}$ & 9.9 & 4.7 & $01 / 2003$ & $\begin{array}{l}\text { Todas las cuotas se eliminan } \\
\text { al ingresar a la OMC }\end{array}$ \\
\hline Papel & 14.2 y 5.5 & 0 & $01 / 2005$ & $\begin{array}{l}\text { Podría eliminarse de acuerdo } \\
\text { con iniciativas de APEC }\end{array}$ \\
\hline
\end{tabular}

Productos

Farmacéuticos

60

9.6 y 4.2

01/2005

Equipo

científico

12.3 a 6.5

0

01/2003

Acero

10.3 a 6.1

0

$01 / 2003$

Textiles y

25.4

11.7

01/2005

La mayoría de las cuotas se

Ropa eliminan con el ingreso a la OMC; el resto después de un año.

\begin{tabular}{lllll} 
Juguetes & 35 & 0 & $01 / 2005$ & De acuerdo con iniciativa de la \\
\hline FuENTE: Chinghity,
\end{tabular}
FUENTE: Chinability, WTO agreement (http ://www.chinability.com/WTO.html) (15/11/2001) 
extranjeras ya habían establecido 191 oficinas de representación y subsidiarias con un total de activos por 36,000 millones de dólares, en 23 localidades.

De conformidad con los compromisos adquiridos para su acceso a la OMC, China realizará aperturas adicionales a la inversión extranjera en las ramas financiera y de seguros, telecomunicaciones y servicios de intermediación. Los nuevos mecanismos de carácter institucional -adicionales al establecimiento de empresas de capital extranjero y join ventures-incluyen fusiones y adquisiciones de empresas ya establecidas. Asimismo, China acordó eliminar para el 2005 las restricciones geográficas y de negocios a las instituciones financieras extranjeras, con lo cual éstas recibirían un trato igual a las nacionales. Los bancos y las compañías de seguros de propiedad estatal perderán la protección que hasta ahora han tenido, lo que intensificará la competencia de los mercados financieros (Jiang, 2001: 19-21; He, 2001:3-12; Lin, 2000; Chinability, 2001)

\section{Las empresas estatales}

Como parte de la reforma económica de China, las empresas estatales experimentaron reestructuraciones muy significativas a finales de los noventa; existe evidencia, por ejemplo, de que aquellas están realizando desintegraciones estratégicas de algunas industrias competitivas en la industria ligera, como textiles, enseres para el hogar, sectores de servicios generales, y aun industrias intensivas en capital como la del cemento

Las relaciones entre las empresas estatales y el gobierno han ido cambiando con el avance en el proceso de La Reforma. Específicamente, se han ido separando las funciones administrativas del gobierno de las de administración de las empresas. Con ello el gobierno busca tener un papel de creador de un ambiente propicio para mantener el orden del mercado, que continuar siendo un jugador activo dentro del mimo. Por otra parte, en los últimos años éste ha propiciado el desarrollo de la economía no estatal y de las empresas pequeñas y medianas. El esquema tradicional de apoyar a los grandes conglomerados está cambiando para apoyar a las empresas más pequeñas, con una mayor flexibilidad, mayor capacidad de adaptación a los cambios y altas tasas de rentabilidad económica (He, 2001, 3-12)

\section{Cambios en la administración pública}

Las reestructuración de los diversos sectores del gobierno constituyen el centro de las reformas en China. La incorporación a la OMC propiciará la profundización de algunas reformas y promoverá otras adicionales. Liu He relaciona diez áreas donde se darían estos cambios:

1.- El sistema de control de inversiones del Estado cambiará de un Sistema de Examen y Aprobación a un Sistema de Registro e Información. De hecho, en el mercado de capital, la admisión al mercado de valores de las compañías públicas está cambiando en este sentido. Por ejemplo, el control de inversiones se realiza por medio de la aprobación independiente de los bancos, en lugar del de la Comisión de Planificación. Se prevé que los mecanismos de mercadojugarán un mayor papel en la ubicación de las inversiones durante el periodo del $10^{\circ}$ Plan Quinquenal (2001-2005).

2.- Establecimiento de un sistema de seguridad social, que será necesario ante la perspectiva de privatización de algunos activos gubernamentales y el mantenimiento de los derechos laborales.

3.- Optimización de un control corporativo para que las demandas de protección de los derechos de propiedad y los intereses del inversionista sean cada vez mejor administrados.

4.- Mayor énfasis en el desarrollo y el aprovechamiento de los recursos humanos. Estas estrategias, aunque ya han sido introducidas, requieren mejorarse para aprovechar mejor los recursos de capital humano. Específicamente es necesario 
introducir estímulos para que los estudiantes que se encuentran en el extranjero regresen a trabajar en áreas estratégicas de China.

5.- Mejorar el sistema de la protección de los derechos de propiedad intelectual.

6.- Ajustar el marco legal para propiciar el desarrollo del sector no estatal. Un número importante de proyectos de ley están pendientes de ser aprobados por los cuerpos legislativos de China.

7.- Cambios adicionales en las leyes y regulaciones para incrementar la tendencia de las inversiones privadas en infraestructuras. Los campos de inversión ya están definidos. Entre estos se cuentan supercarreteras, plantas de energía, abasto y redes de distribución de agua, procesamiento de basura y construcción. Los recursos públicos son insuficientes para cumplir con los proyectos que se requieren.

8.- Cambios en los mecanismo de operación gubernamental, encaminados a mejorar la eficiencia de la burocracia y el desmantelamiento de las áreas donde no se requiere la intervención directa.

9.- Transferencia de algunas funciones gubernamentales hacia las organizaciones de intermediación que tendrán un mayor desarrollo. Algunas de estas organizaciones de intermediación son cruciales para el desarrollo del mercado, como instituciones de inversión, despachos de contadores, firmas de abogados y de valuación.

10.- Cambios en el sistema de la tierra. La ampliación en la escala de las operaciones y la industrialización de los productos agrícolas deben ser acelerados para ayudar a los agricultores a adaptarse a la competencia internacional y elevar sus ingresos. Los cambios en el sistema de la tierra tendrán influencia de gran profundidad.

\section{La relación con Taiwán}

Unas horas después de haberse formalizado el ingreso de China a la OMC, fue aprobado el ingreso de Taiwán. Con ello toda China forma parte de este organismo, ya que Hong Kong y Macao se habían integrado desde hace varios $\operatorname{años}^{3}$.

De acuerdo con algunos analistas económicos, la participación de ambos en la OMC traerá beneficios de carácter comercial y de inversión para ambos lados del estrecho de Taiwán. Por ejemplo, los productos agrícolas chinos verán ampliado su mercado. En preparación a su inserción en la OMC, Taiwán redujo sus tarifas de 20 por ciento a 15.21 por ciento, y para 2006 quedarán en 12.9 por ciento. Los productos industriales bajarán de una tasa nominal de 6.5 por ciento a 5.79 por ciento después del primer año de su ingreso a la OMC a 4.5 por ciento en el 2004 cuando la reducción sea completada. Las más importantes reducciones arancelarias se darán en productos como cerveza y alcohol, equipo médico, muebles y productos de papel que tendrán una arancel de cero, al momento de ingresar a la OMC (TaipeiTimes).

\section{Conclusiones}

Los cambios realizados por China en los últimos 20 años y los compromisos adicionales adquiridos con la OMC, tendrán efectos importantes - de diverso grado, dirección e intensidad- tanto para aquella como para el sistema internacional. Los ajustes de carácter económico, comercial, administrativo, legal y financiero, entre otros, cambiarán aún más la faz de China y acentuarán su participación e influencia en el sistema internacional. El incremento en la eficiencia productiva que se espera en los cambios estructurales la obligarán a intensificar sus relaciones económicas con el exterior. Ello representa un gran reto (¿amenaza?) para múltiples ramas productivas a nivel mundial, pero también una gran oportunidad para los sectores que tienen, en un país con 1,300 millones de habitantes, un gran mercado en constante expansión.

La sociedad china se verá impactada de diversas maneras: entre los beneficiarios inmediatos de estos ajustes están los consumidores, por la reducción de la tarifas de 
importación y la disminución de los precios de algunos bienes. Sin embargo, algunos productores se verán afectados en sus ingresos. La reestructuración productiva demandará la creación y ampliación de servicios sociales para hacer frente a la reducción que se dará en los niveles de empleo con la introducción de nuevas tecnologías.

El acceso de China a la OMC puede apreciarse claramente desde la perspectiva de la integración a una división internacional del trabajo industrial, agrícola y de servicios. La reglas y procedimientos que ha venido aplicando para preparar su ingreso al organismo se ajustan a los objetivos de los regímenes internacionales, económico y comercial, con los que operan las instituciones como la OMC.

La integración de China a la Organización Mundial de Comercio forma parte de la estrategia de reforma económica y social de su dirigencia. Las negociaciones en los diversos foros, entre los cuales APEC fue de los más sobresalientes, dejaron en claro la intención de China de participar más activamente en la economía mundial. El antecedente más inmediato lo encontramos en el impulso a sus políticas de mercado, que se espera sean profundizadas por medio de reformas adicionales en sus estructuras productiva y legal, para propiciar aún más la apertura comercial y la integración al sistema de producción globalizado.

Los chinos del exterior, en especial de Taiwán, verán facilitados los medios para participar en las diversas áreas de la economía de China, desde inversiones en las bolsas de valores hasta inversiones directas o compraventa de bienes y servicios. Hacia el exterior, la participación de China en la OMC, impactará de manera desigual. Algunos países podrán aprovechar mejor el mercado chino y obtener ventajas adicionales, pero otros que no cuentan con sectores competitivos para compensar el comercio deficitario que tienen con ese país, se verán perjudicados, por la mayor facilidad de ingreso de los productos chinos con ventajas comparativas, sobre todo productos industriales y agrícolas intensivos en mano de obra.
Las reglas de la OMC garantizan el acceso no discriminatorio al mercado chino para todos los países miembros. Sin embargo, los que tienen mayor capacidad de participar en éste son los países más avanzados que ya han establecido lazos comerciales y de inversión. Por ejemplo, la venta de productos agrícolas por parte de los Estados Unidos es un área del comercio que quedó bien definido desde la etapa de las negociaciones bilaterales, previas al ingreso de China a la OMC.

Para algunas ramas de la planta productiva de los países subdesarrollados los productos chinos representan retos formidables. Sobresalen las de ropa, algodón, textiles en general, juguetes, calzado, alimentos procesados e informática, en las que China dispone de ventajas comparativas, entre otras razones, por la mano de obra barata. Los tiempos de ajuste son muy cortos; de hecho, el futuro ya está aquí.

\section{Fuentes}

Carter, A. Colin (2001), “China's trade integration and impacts on factor markets", en Yamazawa, Ippei e Imai, Ken-ichi (edit.), China enters WTO:pursuing symbiosis with the global economy, Institute of Developing Economies, Tokio, pp. 71-88.

Chinability, WTO agreement (http ://www.chinability.com/ WTO.html) (15/11/2001)

Du, Ying (2001), “China's agriculture restructuring and system reform under it's accession to WTO”, en Yamazawa, Ippei e Imai, Ken-ichi (edit.), China enters WTO: pursuing symbiosis with the global economy, Institute of Developing Economies, Tokio, pp. 52-60.

Hai, Wen (1998), “The WTO and China's objectives as a world trading power", en China in the new millennium. Market reforms and social development, Cato Institute, Washington, D.C.

He, Liu (2001) "Systematic changes and new institutional arrangement after China's accesion to WTO”, en Yamazawa Ippei e Imai, Ken-ichi (edit.), China enters WTO: pursuing symbiosis with the global economy, Institute of Developing Economies, Tokio.

Hernández H. Roberto (2001), "China's agricultural policy for the $21^{\text {st }}$ century: its influence on international grain markets“, ponencia presentada en el seminario Regional integration in the Pacific Rim: the economic impact, Universidad Tecnológica de Sydney, 23 de Julio de 2001. IAP People's Republic of China 2001, (http//www.apeciap.org/document/PRC _2001_IAP .htm)

Jiang, Xiaojuan (2001), "Foreign investment after China's WTO accession: trends and salient features", en Yamazawa, Ippei e Imai, Ken-ichi (edit.), China enters 
WTO: pursuing symbiosis with the global economy, Institute of Developing Economies, Tokio.

Lin, Justin Yifu (2000), "China's Accession to WTO: Impacts on Agriculture an Financial Sector", Pekin University and Hong Kong University of Science and Technology, No. E2000008, November 3, 2000.

Muzi net. http: //dailynews.muzi.net/11/English/ 1082468.shtml. (14/13/2002)

Taipei Times, Monday, October 15 th, 2001.

WTO/NEWS (http:// www.wto.org/english/news-e/press-1e/pr243_ehtm)

Yamazawa, Ippei e Imai, Ken-ichi (edit.) (2001), China enters WTO: pursuing symbiosis with the global economy, Institute of Developing Economies, Tokio.

\section{Notas}

1 La apreciación de carácter teórico sobre ambos tipos de política internacional la realiza Henry Kissinger dentro del paradigma teórico del Realismo clásico, en su obra $A$ World Restored. El cambio implica que una potencia acepta resolver sus diferencias por medio de la negociación, en el contexto de un orden internacional legítimo.

2 El proceso de reducción arancelaria, de 1996 a la fecha, se ha dado de la siguiente forma: en abril de 1996 la tasa fue disminuida de 35.9 a 23 por ciento; en octubre de 1997 a 17 por ciento; en enero de 1999, en cumplimento con los acuerdos de liberalización voluntaria sectorial anticipada (EVSL), China redujo sus aranceles para productos forestales y juguetes, lo que dio un promedio simple de 16.7 por ciento, mismo que en enero de 2001 llegó a 15 por ciento.

3 Hong Kong se inegró al GATT en abril de 1986 y Macao se convirtió en una parte contratante del GATT en enero de 1991. No obstante que ambas ex colonias se integraron a la soberanía de China a finales del siglo $\mathrm{XX}$, ambas continuan siendo miembros de la OMC usando los nombres de China-Hong Kong y China-

Macao. T!: 